\title{
Melt Superheating on the Microstructure and Mechanical Properties of Diecast Al-Mg-Si-Mn Alloy
}

\author{
Wenchao Yang, Xinliang Yang, and Shouxun $\mathbf{J i}^{*}$ \\ Brunel Centre for Advanced Solidification Technology (BCAST), Brunel University London, \\ Uxbridge, Middlesex, UB8 3PH, United Kingdom
}

(received date: 29 April 2014 / accepted date: 15 September 2014)

\begin{abstract}
The application of aluminium alloys in automotive body structure is one of the main developments in recent years. The increase of the mechanical properties of the ductile die-casting is one of the most critical topics for the application. In this work, the effect of melt superheating on the morphology, size and distribution of $\alpha-\mathrm{Al}$ phase and Fe-rich intermetallics, and on the mechanical properties of the Al-Mg-Si-Mn diecast alloy was investigated. The results showed that the refined microstructure could be obtained through melt superheating. The volume fraction of dendritic $\alpha-\mathrm{Al}$ phase and the Fe-rich intermetallic phase formed in the shot sleeve was significantly reduced, resulting in the refined microstructure. Overall, the melt superheating could improve the mechanical properties of the yield strength, ultimate tensile strength, and elongation of the diecast Al-Mg-Si-Mn alloy. And, the Fe-rich intermetallic phase formed in the shot sleeve with the coarse compact morphology and formed in the die cavity with the fine compact particles were identified as the same $\alpha-\mathrm{Al}_{12}(\mathrm{Fe}, \mathrm{Mn})_{3} \mathrm{Si}$ composition in the present experimental conditions, which was not affected by the melt superheating.
\end{abstract}

Keywords: alloy, mechanical properties, microstructure, solidification, melt superheating

\section{INTRODUCTION}

The application of lightweight materials in car body structure is one of the most recent developments in automotive industry, in which the ductile alloys play a critical role in manufacturing of thin wall components made by high pressure die casting (HPDC). It is more interesting to make the castings with recycled aluminium alloys due to the benefits in economics and environment, in particular the reduction of energy consumption and the conservation of natural resources [1-3]. However, the accumulation of impurity elements in the recycled aluminium alloys is one of the major concerns as it is unavoidable in practice. Although the presence of a small amount of iron in aluminium alloys is beneficial to prevent die soldering in HPDC process [4], the excessive iron has been found to be detrimental to the mechanical properties of Al-Si [5], Al-Si-Cu [6] and Al-Mg-Si-Mn alloys [7-9]. Therefore, many measures are taken to eliminate the detrimental effect of iron, including remove iron and modify the morphology of Fe-rich intermetallic compounds [10-12].

The effects of melt superheating have been interesting for several decades [13]. Although high superheating temperatures

*Corresponding author: shouxun.ji@brunel.ac.uk in aluminium alloys increase energy costs, furnace wear, gas pick-up, and high oxidation loss, an appropriate superheating is still attractive in industry because of its easy operation. The melt superheating was able to improve the fluidity during casting of aluminium alloys $[14,15]$. It was also found that the dendrites become finer with the increase of superheating in the A14Fe2Mn1.5 Monel alloy [16]. For hypereutectic Al$\mathrm{Si}$ alloys, by using superheating treatment, the primary silicon grains were remarkably refined $[17,18]$. The reported effects were that a finer and/or more uniform microstructure, as well as an increase of yield strength, tensile strength and ductility occurred in the samples produced with superheating of the melt before solidification [19,20]. The similar results were also observed in industrial alloys such as A356 [21,22]. On the other hand, low superheating has been confirmed to be able to create globular microstructure with refined primary $\alpha$-Al phase in semisolid processing of aluminium alloys $[23,24]$. Superheating was also reported to be responsible for the loss of effectiveness of the grain refiner in aluminium alloys [25].

In addition, the melt superheating has been reported to affect the Fe-rich intermetallic phases and thus to be able to modify their morphology and size in aluminium alloys [26]. Narayanan et al. [27] investigated the crystallisation behaviour of Fe-containing intermetallic compounds in an industrial 
grade A319 alloy. When the melt was superheated to 200 to $300{ }^{\circ} \mathrm{C}$ above the liquidus temperature, the Fe-rich compounds crystallized in $\alpha$-Fe phase at high cooling rates. For the Al-7Si-0.55Mg alloy without superheating treatment, $\pi$ $\mathrm{Al}_{8} \mathrm{FeMg}_{3} \mathrm{Si}_{6}$ phase was solidified in needle-like shapes with sharp corners. However, after superheated at $900{ }^{\circ} \mathrm{C}$ for 30 minutes, the $\pi-\mathrm{Al}_{8} \mathrm{FeMg}_{3} \mathrm{Si}_{6}$ phase was changed to skeletonlike with hollows inside and rounded corners [28]. Melt superheating was also reported to be able to convert $\beta$-Fe to $\alpha$-Fe in aluminium alloys [29]. For Al-Si alloys, the increased superheating temperature could refine Fe-rich intermetallics. The Chinese script morphology $(\alpha-\mathrm{Fe})$ was produced instead of the platelet morphology $(\beta-\mathrm{Fe})$ at a melt temperature higher than $800^{\circ} \mathrm{C}[30,31]$. Bian et al. [32] reported that the platelet $\beta$-Fe can be transformed into spheroids in Al-Si alloys when using superheated melt and casting into permanent moulds, which gave an increased tensile strength and elongation. These observations are important in understanding the microstructure features of $\mathrm{Al}-\mathrm{Si}$ and $\mathrm{Al}-\mathrm{Si}-\mathrm{Cu}$ cast alloys. However, insight in solidification and microstructural evolution of other alloys is still limited in terms of the morphology, size and distribution of Fe-rich intermetallic phases in the castings with different levels of melt superheating, especially for the alloys solidified under the high cooling rate such as using HPDC process, which can offer a cooling rate at a level of $10^{2} \mathrm{~K} / \mathrm{s}$ in the shot sleeve and $10^{3} \mathrm{~K} / \mathrm{s}$ in the die cavity $[33,34]$. Moreover, the interest in HPDC process is changing from the production of non-structural castings to the manufacturing of structural components, in particular the thin wall castings of Al-Mg-Si-Mn alloys for the car body structural components using recycled alloys. It is therefore significant to maintain the mechanical properties of the Al-Mg-Si-Mn alloys and to reduce the detrimental effect of iron in castings. Melt superheating is a simple and effective approach to refine the microstructure and improve the mechanical properties of diecast $\mathrm{Al}-\mathrm{Mg}-\mathrm{Si}-\mathrm{Mn}$ alloys, which allows an increased tolerance of iron content in the recycled alloys to satisfy the required mechanical properties in application.

In the present study, the effect of melt superheating on the morphology, size and distribution of $\alpha$-Al phases and Fe-rich compounds was investigated in the die casting Al-Mg-SiMn alloy. The mechanical properties of the yield strength, ultimate tensile strength and elongation were assessed with different levels of melt superheating. The discussions were focused on the relationship between melt superheating and the liquid melt structure, nucleation and growth of solidifying phases in the superheated melt, and the relationship between the microstructure and the mechanical properties of diecast Al-Mg-Si-Mn alloys.

\section{EXPERIMENTAL PROCEDURES}

The Al-Mg-Si-Mn alloy with Fe addition was produced by melting the ingots of commercial pure aluminium, pure magnesium and the master alloys of $\mathrm{Al}-15 \mathrm{wt} \% \mathrm{Si}, \mathrm{Al}-20 \mathrm{wt} \% \mathrm{Mn}$, and $\mathrm{Al}-80 \mathrm{wt} \% \mathrm{Fe}$. The alloy was melted with a standard procedure and its composition was analysed by an optical mass spectroscopy after homogenisation $1 \mathrm{~h}$ at different levels of superheat in the melt. The detailed compositions are listed in Table 1. Based on the specific composition, the liquidus temperature $\left(649^{\circ} \mathrm{C}\right)$ of the experimental alloy was calculated using Pandat software developed by Chen et al. [35].

A $4500 \mathrm{kN}$ HPDC machine was used to produce final as-cast samples with different pouring temperatures from $660{ }^{\circ} \mathrm{C}$ to $850^{\circ} \mathrm{C}$. Six ASTM standard samples with three $\phi 6.35 \mathrm{~mm}$ round bars and three square bars were cast in each shot. Figure 1 showed the schematic diagram of casting samples. More detailed descriptions about the sample preparation process could be found in reference [7]. The tensile tests were performed at an Instron 5500 Universal Electromechanical Testing System equipped

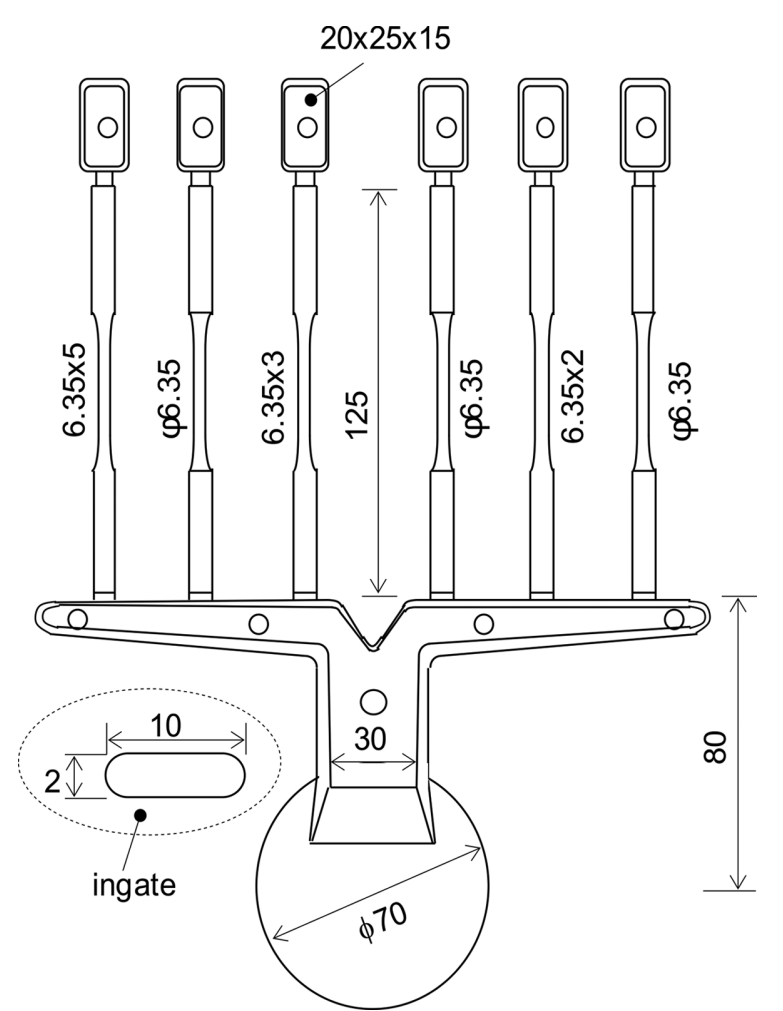

Fig. 1. Diagram of die casting for the standard tensile testing samples of aluminium alloys according to the specification defined in ASTM B557-06. The overflow and biscuit are designed in association with $4500 \mathrm{kN}$ cold chamber die casting machine (all dimensions are given in $\mathrm{mm}$ ).

Table 1. Compositions of the diecast Al-Mg-Si-Mn alloys used in experiments (wt\%)

\begin{tabular}{cccccccc}
\hline $\mathrm{Si}$ & $\mathrm{Fe}$ & $\mathrm{Mn}$ & $\mathrm{Mg}$ & $\mathrm{Ti}$ & $\mathrm{Zn}$ & Others & $\mathrm{Al}$ \\
\hline $2.36 \pm 0.15$ & $0.98 \pm 0.02$ & $0.56 \pm 0.02$ & $5.28 \pm 0.20$ & $0.086 \pm 0.01$ & $0.007 \pm 0.002$ & $<0.03$ & bal. \\
\hline
\end{tabular}


with Bluehill software and a $\pm 50 \mathrm{kN}$ load cell. Each data reported was based on the properties obtained from 10 to 20 samples without showing obvious casting defects on the fractured surfaces.

Microstructures of the as-cast samples were investigated by optical microscopy, conventional scanning electron microscope (SEM) and scanning transmission electron microscope (STEM). SEM was carried out on a Zeiss Supera 35 instrument equipped with a field emission gun and energy dispersive spectroscopy (EDS) facilities and operated at an accelerating voltage of $15 \mathrm{kV}$ to indentify the composition and morphology of intermetallic particles. And, STEM composition mapping for intermetallic particles was performed on a Tecnai FEG F30 instrument equipped with EDS facility operated at $300 \mathrm{kV}$ accelerating voltage. The particle size, volume fraction and the shape factor of solid phases were measured using an AxioVision 4.3 Quantimet digital image analysis system. To prepare thin foils for STEM examination, slices cut from the as-cast HPDC samples were mechanically ground and cut into $3 \mathrm{~mm}$ diameter discs. These discs were then ground to a thickness of less than $100 \mu \mathrm{m}$ and finally ion-beam thinned on a Gatan precision ion polishing system at a voltage of $5.0 \mathrm{kV}$ and an incident angle of $4 \sim 6^{\circ}$.

\section{RESULTS}

\subsection{As-cast microstructure at different levels of melt super- heating}

In the as-cast state, there was a significant change in the morphologies of the $\alpha$-Al phase obtained with different levels of melt superheating in the diecast Al-Mg-Si-Mn alloy. Fig. 2 and Fig. 3 showed the optical and backscattered electron SEM microstructures of the alloy cast at $660^{\circ} \mathrm{C}$ and $850{ }^{\circ} \mathrm{C}$, respectively. When the casting was made at low melt superheating, i.e., $660{ }^{\circ} \mathrm{C}$, as shown in Fig. 2 , the $\alpha$-Al phase displayed two types of morphology, which were labelled as ' $\alpha$ ' ' and ' $\alpha 2$ ' in Fig. 2a. The $\alpha_{1}$-Al phase exhibited dendrites and fragmented dendritic morphology, which was formed during the solidification in the shot sleeve. The $\alpha_{2}$-Al phase displayed fine globular morphology, which was formed in the die cavity. It was clear that the $\alpha_{1}$-Al phase presented at different sizes from $15 \mu \mathrm{m}$ to $100 \mu \mathrm{m}$ with a mean of $43 \mu \mathrm{m}$. However, compared with the coarse $\alpha_{1}-\mathrm{Al}$ phase, $\alpha_{2}$-Al phase had a smaller size from $3 \mu \mathrm{m}$ to $10 \mu \mathrm{m}$ with an average of $7.5 \mu \mathrm{m}$. And, these coarse $\alpha_{1}$-Al phase were isolated by fine globular $\alpha_{2}$-Al phase in the microstructure. The remaining interdendritic regions were characterised as a eutectic microstructure from $\alpha$ - $\mathrm{Al}$ matrix and $\mathrm{Mg}_{2} \mathrm{Si}$ phase, which was presented as lamellar structure. However, if the casting was made at $850^{\circ} \mathrm{C}$, i.e., with a superheating of $200{ }^{\circ} \mathrm{C}$, only $\alpha_{2}$ - $\mathrm{Al}$ phase with a fine globular morphology were observed, which were formed in the die cavity as shown in Fig. 3. It was obvious that those coarse $\alpha_{1}$-Al phase with dendrites and fragmented dendritic mor-
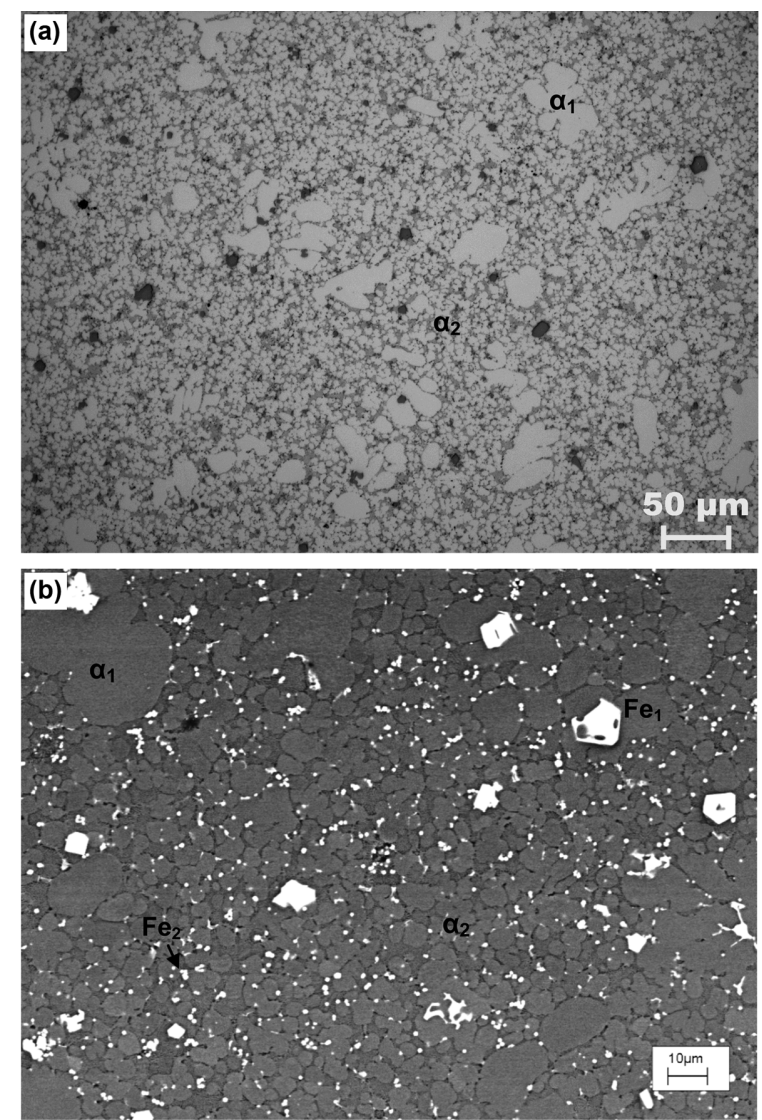

Fig. 2. Micrographs showing the morphology of primary $\alpha-\mathrm{Al}$ phase and Fe-rich intermetallics in the diecast Al-Mg-Si-Mn alloy at a melt temperature of $660^{\circ} \mathrm{C}$, (a) optical image for overall microstructure, (b) backscattered SEM for the detail morphology of the primary $\alpha$-Al phase and Fe-rich intermetallics.

phology had basically disappeared. The results confirmed that the formation of $\alpha$-Al phase in the shot sleeve could be reduced or eliminated with sufficient melt superheating.

Another significant change was also observed in the morphologies of Fe-rich compounds with different levels of melt superheating. In Fig. 2, it was seen that, when the casting was made at a low melt superheating, there were two types of Fe-rich intermetallics observed in the microstructure, which were also labelled as ' $\mathrm{Fe}_{1}$ ' and ' $\mathrm{Fe}_{2}$ ' in Fig. 2b. The $\mathrm{Fe}_{1}$-rich intermetallics were associated with the $\alpha_{1}$-Al phase and exhibited coarse compact morphology, which were found in tetragonal, pentagonal, hexagonal shapes. The $\mathrm{Fe}_{1}$-rich intermetallics were identified by SEM-EDS quantification to be $\alpha$ $\mathrm{AlFeMnSi}$ with the typical composition of $\alpha-\mathrm{Al}_{12}(\mathrm{Fe}, \mathrm{Mn})_{3} \mathrm{Si}$ (see Table 2, which gave the quantitative SEM/TEM-EDS results of the chemistry for the Fe-rich intermetallics in the $\mathrm{Al}-\mathrm{Mg}-\mathrm{Si}-\mathrm{Mn}$ diecast alloy). Meanwhile, the fine intermetallics (labelled as $\mathrm{Fe}_{2}$ ) were also found in association with the $\alpha_{2}$ - $\mathrm{Al}$ phase and segregated in $\alpha$-Al grain boundaries and inside the $\alpha$-Al grains. However, when the melt superheating was increased to a level of $200{ }^{\circ} \mathrm{C}$ over its liquidus tempera- 

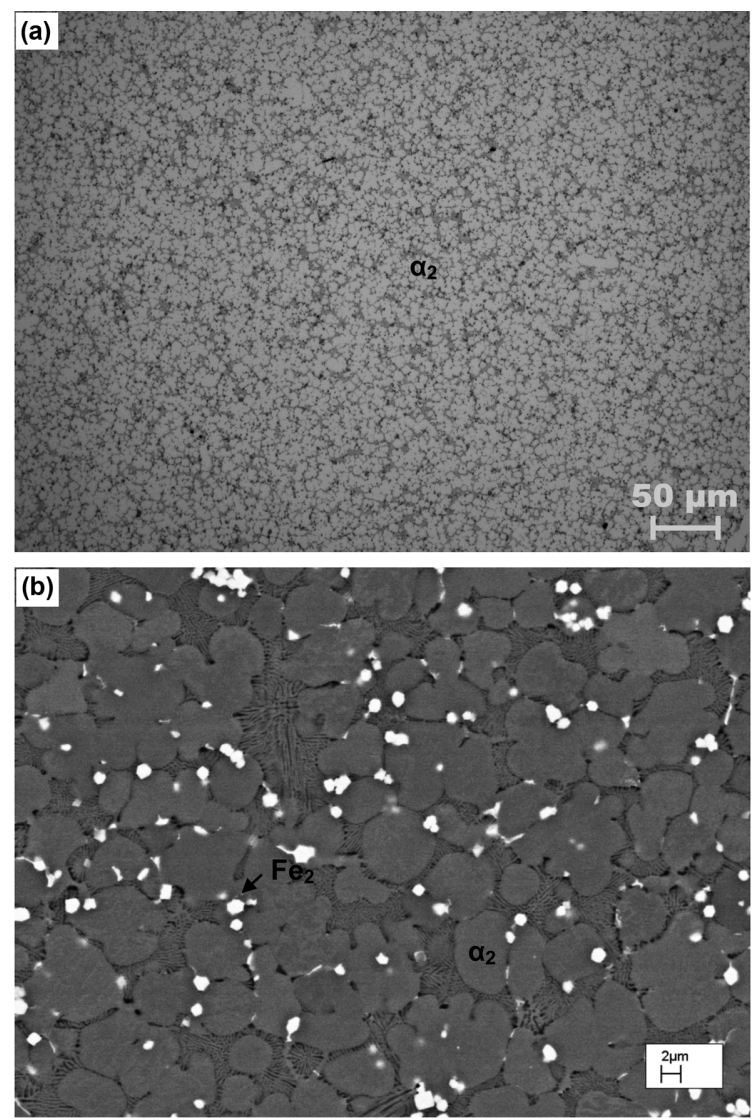

Fig. 3. Micrographs showing the morphology of primary $\alpha-\mathrm{Al}$ phase and Fe-rich intermetallics in the diecast Al-Mg-Si-Mn alloy at a melt temperature of $850^{\circ} \mathrm{C}$, (a) optical image for overall microstructure, (b) backscattered SEM for the detail morphology of the primary $\alpha-\mathrm{Al}$ phase and Fe-rich intermetallics.

ture, as shown in Fig. 3. The large compact $\mathrm{Fe}_{1}$-rich intermetallics was not observed and only fine compact $\mathrm{Fe}_{2}$-rich intermetallic particles were seen in the matrix.

The detail composition mapping for the fine $\mathrm{Fe}_{2}$-rich particles was obtained by STEM as shown in Fig. 4. It was obvious that these fine $\mathrm{Fe}_{2}$-rich particles only contained $\mathrm{Al}, \mathrm{Fe}$, $\mathrm{Mn}$ and $\mathrm{Si}$ elements in the experimental alloy, no any $\mathrm{Mg}$ enrichment could be observed. In fact, Mg element mainly dissolved into the $\alpha$-Al phase and segregated in the eutectic area in the form of $\mathrm{Mg}_{2} \mathrm{Si}$ phase. These $\mathrm{Fe}_{2}$-rich intermetallics could been further identified by TEM-EDS quantification to be the same $\alpha-\mathrm{Al}_{12}(\mathrm{Fe}, \mathrm{Mn})_{3} \mathrm{Si}$ composition as the $\mathrm{Fe}_{1}$-rich intermetallics. In addition, the Fe-rich intermetallic compounds were also identified as the same formula of $\alpha-\mathrm{Al}_{12}(\mathrm{Fe}, \mathrm{Mn})_{3} \mathrm{Si}$ at different levels of melt superheating, which was consistent with the previous research [7]. The results confirmed that the melt superheating did not modify the composition of the $\alpha$ AlFeMnSi intermetallics in the diecast Al-Mg-Si-Mn alloy.

Figure 5 further showed the average size of the coarse $\alpha_{1}{ }^{-}$ $\mathrm{Al}$ phase, and the size and distribution of the $\mathrm{Fe}_{1}$-rich intermetallic phase formed in the shot sleeve. It was seen that the sizes of $\alpha_{1}$-Al phase slightly reduced from $45 \mu \mathrm{m}$ to $40 \mu \mathrm{m}$ (Fig. 5a) and the $\mathrm{Fe}_{1}$-rich particle sizes reduced from $11 \mu \mathrm{m}$ to $7 \mu \mathrm{m}$ (Fig. 5b), respectively, when the melt temperature was increased from $660^{\circ} \mathrm{C}$ to $750{ }^{\circ} \mathrm{C}$. The further increase of the melt temperature resulted in the disappearance of the coarse $\alpha_{1}$ - $\mathrm{Al}$ phase and $\mathrm{Fe}_{1}$-rich particles. The distribution of the $\mathrm{Fe}_{1}$-rich particles was matched by the normal distribution curve with an average of $7.3 \mu \mathrm{m}$ (Fig. 5c). The results indicated that the coarse $\alpha_{1}-\mathrm{Al}$ phase and $\mathrm{Fe}_{1}$-rich phase formed in the shot sleeve might be refined by melt superheating.

The effect of melt temperature on the formation of $\alpha_{2}$-Al phase and $\mathrm{Fe}_{2}$-rich particles in the die cavity was shown in Fig. 6. It was seen that the particles sizes of $\alpha_{2}$-Al phase and the average size of the $\mathrm{Fe}_{2}$-rich intermetallics solidified in the die cavity were obviously different from that formed in the shot sleeve. However, both of them had no obvious difference with the increase of melt temperatures (Figs. 6a and b) and the distribution of the Fe-rich particles was roughly matched by the normal distribution curve with an average of $0.76 \mu \mathrm{m}$ (Fig. 6c). However, the variation was small and within the standard deviation. Therefore, the results in Figure 6 indicated that the solidification in the die cavity might be hardly affected by the melt superheating in the experimental ranges. However, it was still noted that the measurement for the grains of $\mathrm{Fe}_{2}$-rich intermetallics was possibly not sufficiently accurate to define the actual size in current experimental facilities, in particular at the magnification of optical microscopy.

In order to further confirm the grain refinement, the number density of $\mathrm{Fe}_{2}$-rich particles was analysed against the melt temperatures in the die cavity. The number density was defined as the numbers of a specified phase in a unit area. The result was shown in Fig. 7. The number density of the $\mathrm{Fe}_{2}$-rich particles formed in the die cavity was slightly increased with the increase of the melt temperature. When the melt temperatures were increased from $660{ }^{\circ} \mathrm{C}$ to $850{ }^{\circ} \mathrm{C}$, the number density was increased from $0.069 / \mu \mathrm{m}^{2}$ to $0.076 / \mu \mathrm{m}^{2}$, which showed $10 \%$ increase of the number density with $200{ }^{\circ} \mathrm{C}$ melt superheating, indicating that a refinement might be achieved for the $\mathrm{Fe}_{2}$-rich intermetallics formed in the die cavity.

Table 2. Average compositions of Fe-rich intermetallic phases measured by SEM-TEM/EDX analysis in the diecast Al-Mg-Si-Mn alloys

\begin{tabular}{ccccccc}
\hline \multirow{2}{*}{ Phase morphology } & \multirow{2}{*}{ Identified compounds } & $\mathrm{Al}$ & $\mathrm{Fe}$ & $\mathrm{Mn}$ & $\mathrm{Si}$ & $\mathrm{Fe} / \mathrm{Mn}$ \\
\cline { 3 - 7 } & & & & $\mathrm{at} \%$ & & \\
\hline coarse compact & $\mathrm{Al}_{12}(\mathrm{Fe}, \mathrm{Mn})_{3} \mathrm{Si}$ & 76.64 & 11.83 & 5.95 & 6.27 & 1.99 \\
fine compact & $\mathrm{Al}_{12}(\mathrm{Fe}, \mathrm{Mn})_{3} \mathrm{Si}$ & 75.47 & 12.16 & 6.28 & 6.09 & 1.94 \\
\hline
\end{tabular}




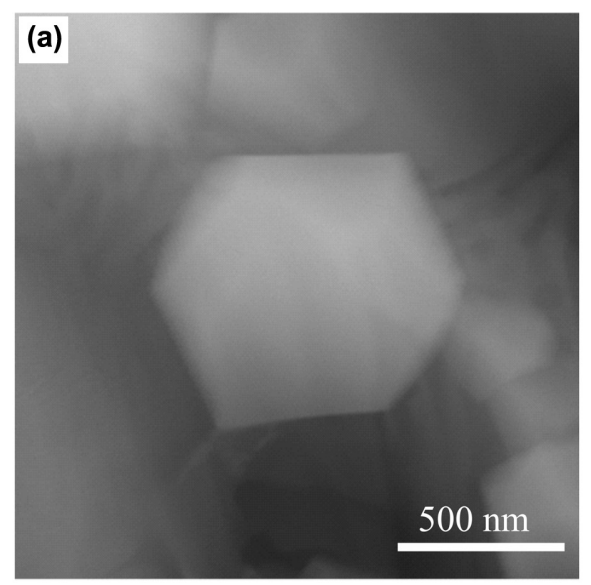

Electron Image 1

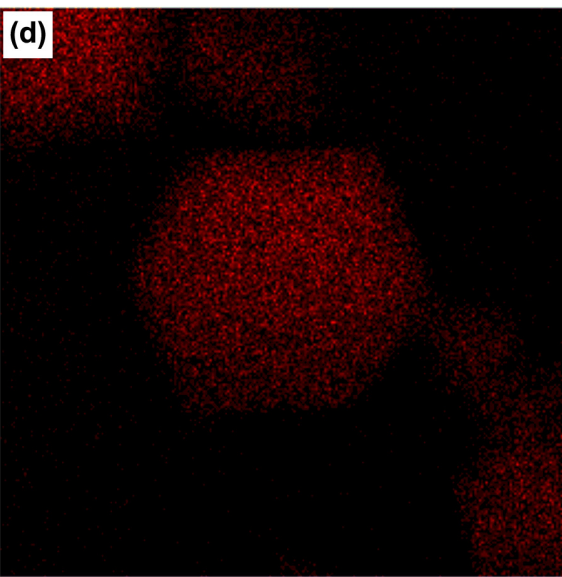

Mn Ka1

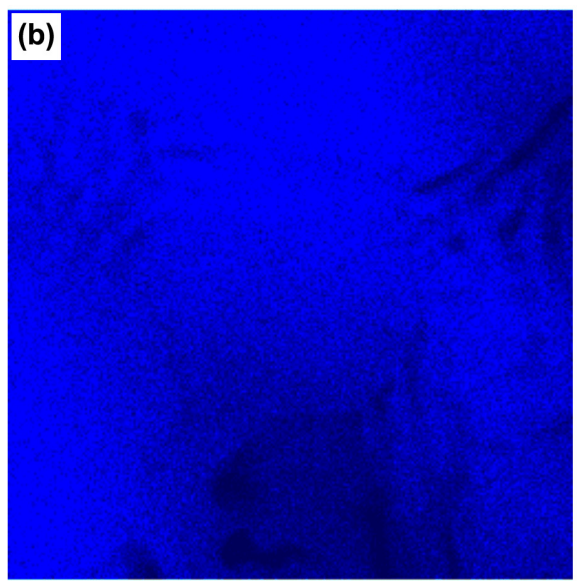

Al Ka1

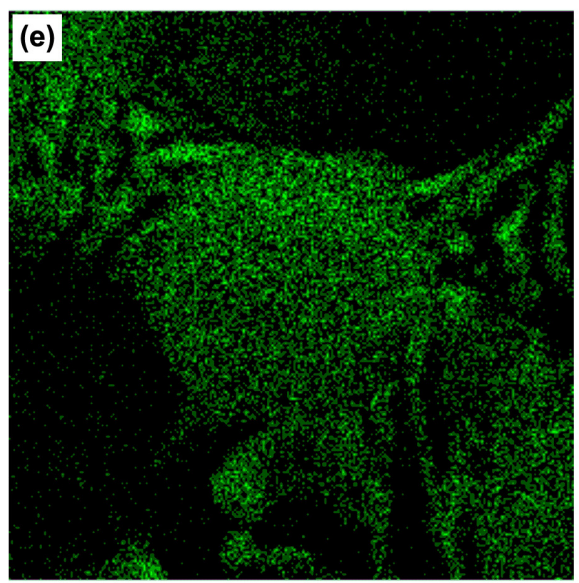

Si Ka1

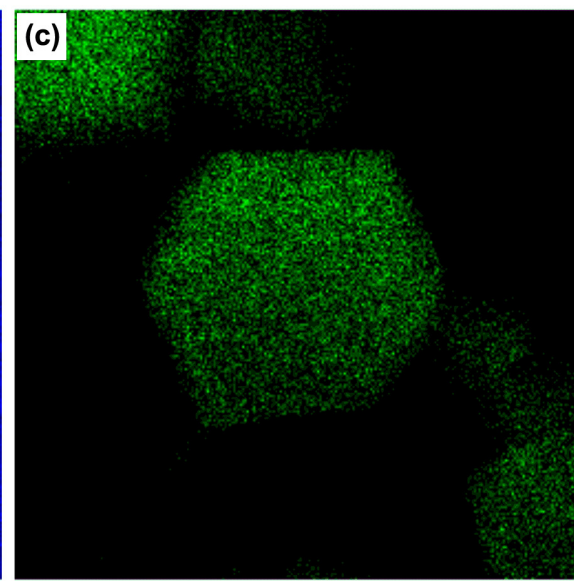

Fe Ka1

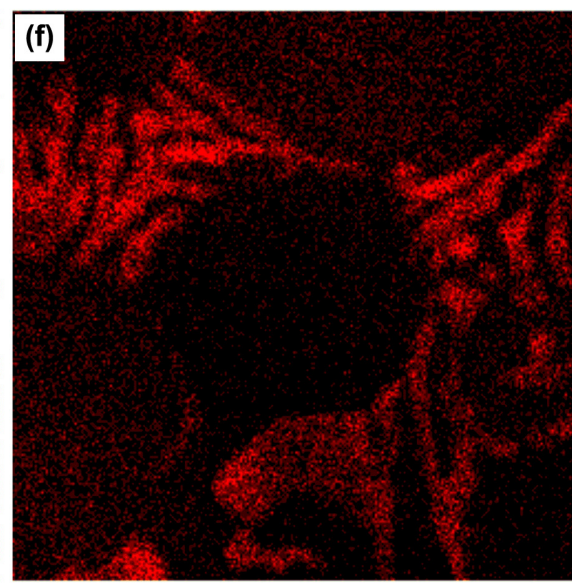

Mg Ka1_2

Fig. 4. Composition mapping of fine Fe-rich intermetallics in the Al-Mg-Si-Mn diecast alloy. (a) STEM image, (b) Al mapping, (c) Fe mapping, (d) Mn mapping, (e) Si mapping, and (f) Mg mapping.
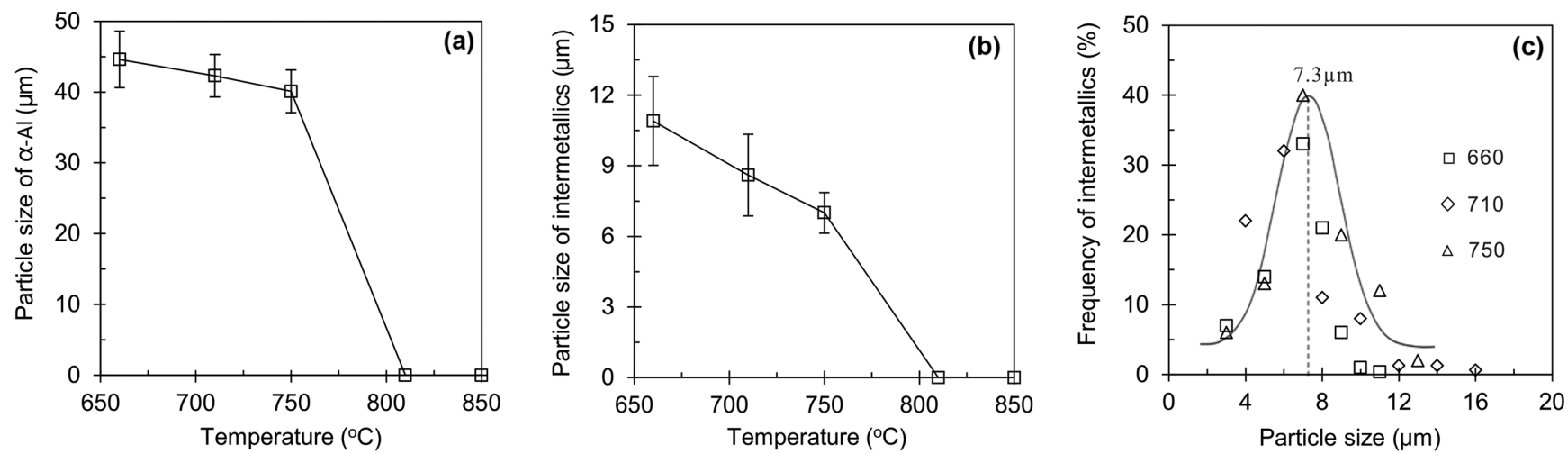

Fig. 5. Effect of melt temperature on (a) the average size of the coarse $\alpha_{1}$-Al phase, (b) the average size of the Fe $\mathrm{e}_{1}$-rich intermetallic phase, and (c) the distribution of $\mathrm{Fe}_{1}$-rich intermetallic phase of the diecast $\mathrm{Al}-\mathrm{Mg}-\mathrm{Si}-\mathrm{Mn}$ alloy solidified in the shot sleeve.

\subsection{Mechanical Properties at different levels of melt super-} heating

Mechanical properties of the diecast Al-Mg-Si-Mn alloys with different levels of melt temperatures were presented in Fig. 8. It was seen that an enhancement in the yield strength, the ultimate tensile strength and the elongation was observed in the alloys with increased melt superheating in the experimental ranges. The overall increase of the yield strength, the ultimate tensile strength and the elongation of the diecast samples was $6.9 \%, 5.5 \%$ and $7.2 \%$, respectively, while the melt 

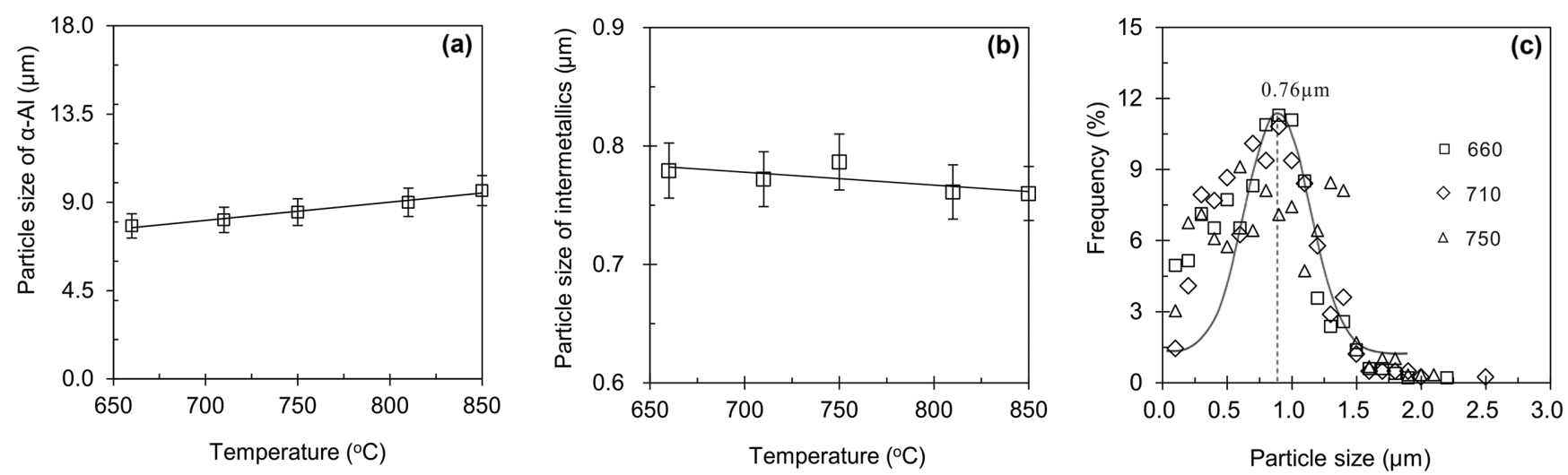

Fig. 6. Effect of melt temperature on (a) the average size of the fine $\alpha_{2}$-Al phase, (b) the average size of the $\mathrm{Fe}_{2}$-rich intermetallic phase, and (c) the distribution of $\mathrm{Fe}_{2}$-rich intermetallic phase of the diecast $\mathrm{Al}-\mathrm{Mg}$-Si-Mn alloy solidified in the die cavity.

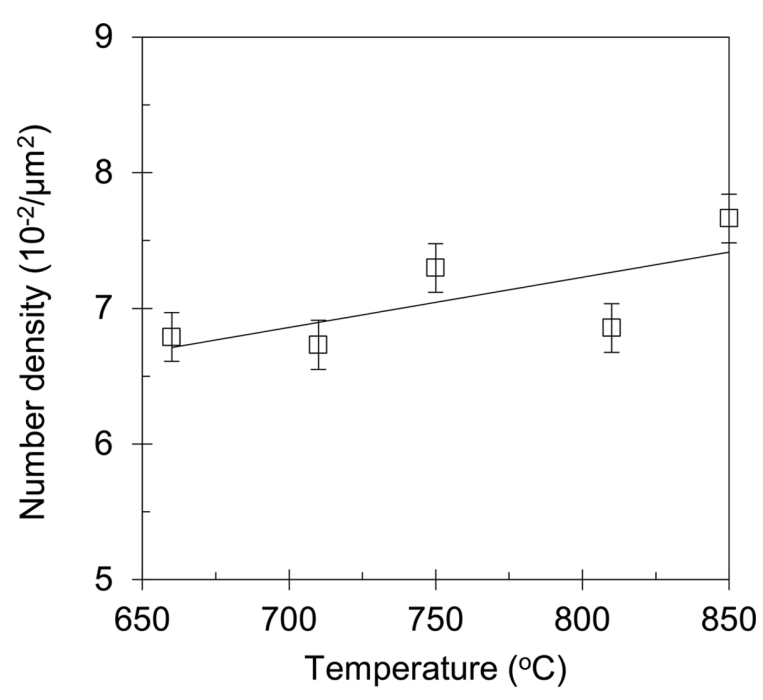

Fig. 7. Effect of melt temperature on the number density of $\mathrm{Fe}_{2}$-rich intermetallic particles in the diecast Al-Mg-Si-Mn alloy formed in the die cavity. temperature increased from $660{ }^{\circ} \mathrm{C}$ to $850{ }^{\circ} \mathrm{C}$. The results confirmed that a relatively high melt superheating might be an effective approach to improve the mechanical properties of diecast Al-Mg-Si-Mn alloys.

\subsection{Thermodynamics calculation of the multi-component Al-Mg-Si-Mn-Fe system}

Finally, a thermodynamic calculation was performed using Pandat software [34] to examine the solidification process and phase fraction in the multi-component Al-Mg-Si-Mn-Fe system. During the calculation, the Ti and other low levels of elements were not considered. The relationship between the phase fraction and the temperature was shown in Fig. 9. It was clear that the phase formation followed $\mathrm{L} \rightarrow \alpha-\mathrm{Al}_{12}(\mathrm{Fe}, \mathrm{Mn})_{3} \mathrm{Si}$ $+\alpha-\mathrm{Al}+\mathrm{Mg}_{2} \mathrm{Si}$, and the primary phase was actually $\alpha-\mathrm{Al}_{12}(\mathrm{Fe}$, $\mathrm{Mn})_{3} \mathrm{Si}$ in the experimental alloy. The $\alpha-\mathrm{Al}_{12}(\mathrm{Fe}, \mathrm{Mn})_{3} \mathrm{Si}$ phase was emerged at $649^{\circ} \mathrm{C}, \alpha-\mathrm{Al}$ was emerged at $620^{\circ} \mathrm{C}$ and the $\mathrm{Mg}_{2} \mathrm{Si}$ phase was created at $590^{\circ} \mathrm{C}$. After solidification, the phase fraction of $\alpha-\mathrm{Al}$ in the alloy was over $90 \%$ and the total of $\alpha-\mathrm{Al}_{12}(\mathrm{Fe}, \mathrm{Mn})_{3} \mathrm{Si}$ and $\mathrm{Mg}_{2} \mathrm{Si}$ was less than $7 \%$. All the other phases were negligible.
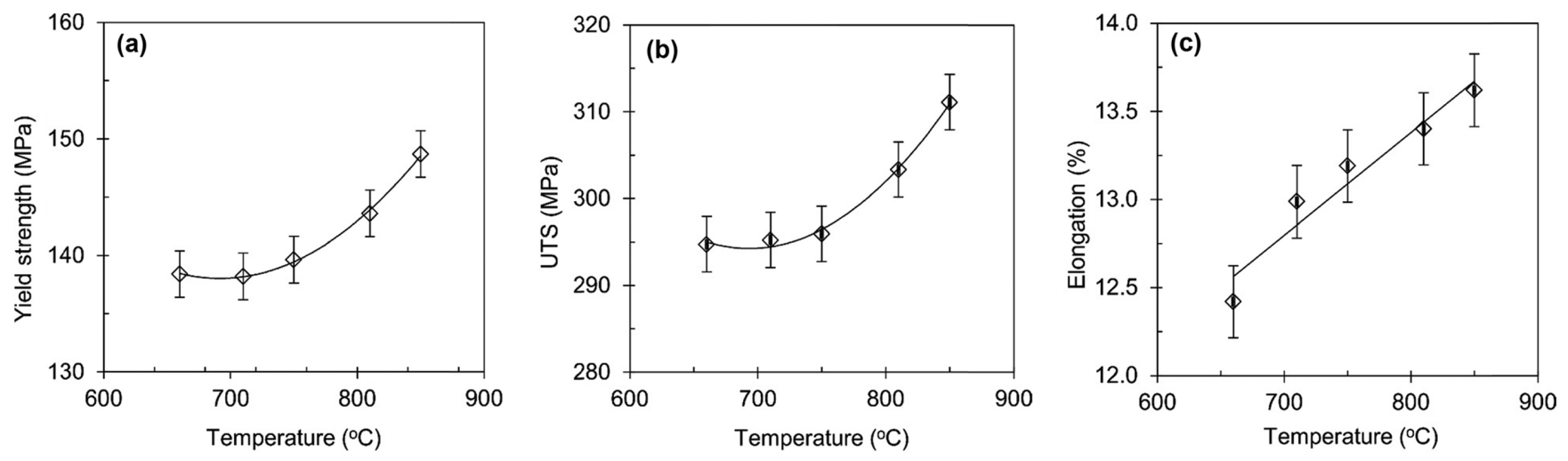

Fig. 8. Effect of melt temperature at different levels of superheating on the mechanical properties of the diecast Al-Mg-Si-Mn alloy, (a) yield strength, (b) ultimate tensile strength, and (c) elongation. 


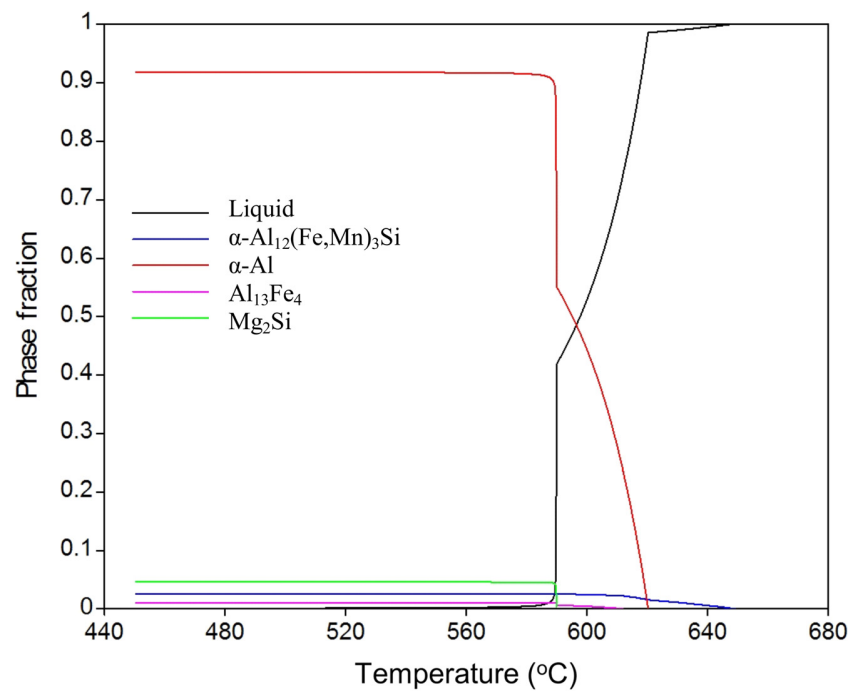

Fig. 9. The phase fraction during the solidification in the experimental alloy calculated by Pandat software using non-equilibrium Scheil method.

\section{DISCUSSION}

\subsection{Melt superheating and liquid structure}

It has been a widely accepted view that the liquid has shortrange order structure that varies gradually with temperature and/or pressure from the melting point to the elevated point. Simulations [36] and experimental results in some binary alloys of $\mathrm{Pb}-\mathrm{Sn}$ [37], Pb-Bi [38], In-Sn [39], and In-Bi [40] had already suggested that the temperature-induced structural change could discontinuously occur at ordinary pressure and over the liquidus in multiple component liquids with a constant chemical composition. The X-ray diffraction of the multi component melts showed that the short-range order in liquid metals depended on the melt temperature in the alloy systems of Al-Si [41,42], Al-Ti [43] and Al-Fe [44]. Therefore, it is generally believed that the liquid has a non-uniform structure at a temperature close to its liquidus. And the non-uniformity can be improved with the increase of melt superheating.

In the melt, the atoms of solute elements do not distribute uniformly with the solvent element before the breaking of their covalent bonds, whereas they aggregate to some extent in microscopic zones surrounded by the domains composed mainly of solvent atoms, showing a kind of metastable local ordering in a range above its liquidus temperature. It has also been suggested in molten Al-Si alloy that there exist metastable phases enriched in Si because of a non-Arrhenius behaviour of physical properties [45]. When temperature is elevated to the extent that the covalent bonds are broken, the kinetic energy of the atoms is high enough to drive them to diffuse into the opposite domains of each other. At the same time, new atomic bonds build up, with the relatively uniform melt forming. Since the melt is mainly composed of solvent, after the reconstruction, a reference solvent atom is surrounded by the nearest shell made up of several solvent atoms and one or two solute atoms in form of clusters, and the bond length difference between the solvent-solvent bonds (no longer the covalent bonds) and the solute-solvent bonds leads to the change in liquid structure because of the variation of the atomic interaction and the adjustment of the atomic bonds. Consequently, the cluster size becomes smaller with increase superheating and the number density in the unit volume of melt is also increased (Fig. 7). The solidification mechanism may be the same as a liquid alloy cooled from a temperature close to the liquidus temperature. The nucleation process is affected by the variation of the cluster size, which is potential become embryos to form initial microstructure during solidification.

\subsection{Nucleation and growth in a superheated melt}

The irreversible atom cluster and the average size of atom group in the alloy melt become smaller with increasing melt temperature. This decreases the number of inhomogeneous nucleation sites and increases the nucleation undercooling. According to the classic nucleation theory, we can have following Eq. [46]:

$$
\begin{aligned}
& \Delta G_{V}=L_{V} \Delta T / T_{m} \\
& \Delta G^{*}=16 / 3 \cdot \pi \sigma /\left(\Delta G_{V}-\Delta G_{S}\right) \\
& I=K \cdot \exp \left(-\Delta G^{*} / k T\right) \exp (-Q / k T) \\
& r^{*}=2 \sigma T_{m} / L_{V} \Delta T
\end{aligned}
$$

where $\Delta T$ is the undercooling, $\Delta G_{V}$ is the change of volume free energy, $L_{V}$ is the latent heat of fusion per unit volume. $T_{m}$ is equilibrium melting temperature, $\Delta G_{S}$ is the change of area free energy, $\sigma$ is the specific area free energy, $I$ is the nucleation rate, $K$ is the proportional constant, $\Delta G^{*}$ is the nucleation energy; $Q$ is the diffusion activation energy; $k$ is the Boltzmann constant; $\Delta G^{*}$ is the critical nucleating energy; $r^{*}$ is the critical nucleation radius and $T$ is the thermodynamics temperature.

From equation (1) to (4), the increase of undercooling $\Delta T$ leads to the increase of $\Delta G_{V}$. The increase of $\Delta G_{V}$ results in the decrease of the critical nucleating energy $\Delta G^{*}$ if other parameters are not changed. The nucleation rate $I$ increases and the critical nucleation radius $r^{*}$ decreases with the increase of undercooling. This indicates that the atom clusters which are less than critical nucleation radius can become stable nucleation site with increasing undercooling. Obviously, either the nucleation rate $I$ increases or the critical nucleation radius decreases can refine grains under the large undercooling. In addition, the increased nucleation rate results in the increased number of grains growing simultaneously. Therefore, the growth time of solidified phase reduces with the increase of melt superheating so that the size of solidified phase decreases. This leads to the grain refinement in the as-cast 
microstructure. Moreover, in HPDC process, the cooling rate in the die cavity is much bigger than that in the shot sleeve, which provides higher undercooling and therefore leading the formation of fine Fe-rich particles in the as-cast microstructure.

Generally, solidification process occurs in two stages in HPDC. One is in the shot sleeve and the other is in the die cavity. The solidification in the shot sleeve commences immediately after the melt is undercooled by the shot sleeve. Obviously the melt in contact with the internal surface of the shot sleeve is undercooled first, leading to the formation of coarse primary phase due to the relatively lower cooling rate. Because the melt in contact with the shot sleeve is in a small proportion and the time between the pouring and the injection is short, the melt is immediately mixed when it is pushed forward in the shot sleeve. When the melt passes through the ingate into the die cavity, the melt is sheared and mixed. Although the solidification process in HPDC is different to the other casting process, the nucleation and growth theory are still valid. Clearly, the increased melt superheating leads to the decreased or eliminated undercooling in the shot sleeve. Therefore, the primary phase formed in the shot sleeve is significantly reduced with the increased melt superheat. This is another importation aspect to understand the alternation of microstructure under varied superheat.

\subsection{Microstructure and property relationship}

The experimental results have confirmed that a relatively high melt superheating improves the mechanical properties of the Al-Mg-Si-Mn alloy. The yield strength, ultimate tensile strength and the elongation of the diecast Al-Mg-Si-Mn alloy increase with an increased melt superheating in the experimental ranges. Referring to the solidification microstructure, the enhanced mechanical properties are believed to correspond to the refinement of Fe-rich intermetallic compounds and a$\mathrm{Al}$ phase. Actually, the refinement includes two aspects. One is the refinement for the grains formed in the shot sleeve and in the die cavity with increase of melt superheating (Fig. 5 and Fig. 6). With the melt superheating, the higher density $\mathrm{Fe}_{2}$-rich intermetallics can be obtained, which will become the effective obstacles of dislocations movement to improve the yield strength. The other is the disappearance of the coarse $\mathrm{Fe}_{1}$-rich intermetallics formed in the shot sleeve with increase of the melt superheating so that these coarse $\mathrm{Fe}_{1}$-rich intermetallics have no chance to be the crack sources resulting from the stress concentration. Therefore, the detrimental effect of the coarse $\mathrm{Fe}_{1}$-rich intermetallics on the mechanical properties is diminished, resulting in the improvement in the mechanical properties observed in the Al-Mg-Si-Mn alloy.

\section{CONCLUSIONS}

(1) During high pressure die casting of the Al-Mg-Si-Mn alloy, the mechanical properties of the yield strength, ultimate tensile strength and elongation are improved with a relatively high melt superheating.

(2) A relatively high melt superheating results in the refinement of both the $\alpha$-Al phase and the $\alpha$-AlFeMnSi intermetallics formed in the shot sleeve and in the die cavity, although the refinement for the microstructure in the die cavity is not as significant as that formed in the shot sleeve because of the high cooling rate in the die cavity.

(3) Melt superheating does not alter the composition of the $\alpha$-AlFeMnSi intermetallic phases formed in the shot sleeve at lower cooling rates and in the die cavity at higher cooling rates, respectively. The coarse compact intermetallics formed in the shot sleeve have the same formula as the fine one formed in the die cavity with both of them being identified as $\alpha$ $\mathrm{Al}_{12}(\mathrm{Fe}, \mathrm{Mn})_{3} \mathrm{Si}$.

\section{ACKNOWLEDGEMENT}

The financial support from Technology Strategy Board (TSB) under project No. 101172 is acknowledged. The authors also would like to thank the EPSRC (UK) and Jaguar Cars Ltd. (UK) for financial support under the grant for the EPSRC Centre - LiME.

\section{REFERENCES}

1. R. Quinkertz, G. Rombach, and D. Liebig, Resour. Conserv. Recy. 33, 217 (2001).

2. European Aluminium Association, Aluminium Recycling in Europe, http://www.world-aluminium.org/media/filer public/2013/01/15/f10000217.pdf(2013).

3. H. Yang, S. Ji, D. Watson, M. White, and Z. Fan, Mater. Sci. Forum, 794-796, 1077 (2014).

4. L. Wang, M. Makhlouf, and D. Apelian, Int. Mater. Rev. 40, 221 (1995).

5. J. Z. Yi, Y. X. Gao, P. D. Lee, and T. C. Lindley, Mater. Sci. Eng. A 386, 396 (2004).

6. G. B. Winkelman, Z. W. Chen, D. H. StJohn, and M. Z. Jahedi, J. Mater. Sci. 39, 519 (2004).

7. S. Ji, W. Yang, F. Gao, D. Watson, and Z. Fan, Mater. Sci. Eng. A, 564, 130 (2013).

8. W. Yang, S. Ji, X. Zhou, I. Stone, G. Scamans, G. E. Thompson, and Z. Fan, Mater. Mater. Trans. A, 45, 3971 (2014).

9. H. Yang, D. Watson, Y. Wang, and S. Ji, J. Mater. Sci. 49, 8412 (2014).

10. L. F. Zhang, J. W. Gao, L. Nana, W. Damoah, and D. G. Robertson, Mineral Processing \& Extractive Metall. Rev. 33, 99 (2012).

11. X. Fang, G. Shao, Y. Q. Liu, and Z. Fan, Mater. Sci. Eng. A 445-446, 65 (2007).

12. L. A. Narayanan, F. H. Samuel, and J. E. Gruzleski, Metall. Mater. Trans. A 26, 2161 (1995). 
13. Z. W. Chen, W. Q. Jie, and R. J. Zhang, Mater. Lett. 59, 2183 (2005).

14. M. Sabatino, L. Arnberg, S. Rørvik, and A. Prestmo, Mater. Sci. Eng. A 413-414, 272 (2005).

15. E. Taghaddos, M. M. Hejazi, R. Taghiabadi, and S. G. Shabestari, J. Alloys. Comp. 468, 539 (2009).

16. F. Wang, J. T. Zou, X. H. Wang, and Z. K. Fan, Trans. Nonferrous Met. Soc. China 19, 19 (2009).

17. H. S. Dai and X. F. Liu, Mater. Charact. 59, 1559 (2008).

18. P. Li, V. I. Nikitin, E. G. Kandalova, and K. V. Nikitin, Mater. Sci. Eng. A 332, 371 (2002).

19. W. Wang, X. Bian, J. Qin, and S. I. Syliusarenko, Metall. Mater. Trans. A 31, 2163 (2000).

20. S. Hegde and K. N. Prabhu, J. Mater. Sci. 43, 3009 (2008).

21. R. Venkataramani, R. Simpson, and C. Ravindran, Mater, Charact, 35, 81 (1995).

22. J. Wang, S. He, B. Sun, Q. Guo, and M. Nishio, J. Mater. Pro. Tech. 141, 29 (2003).

23. Z. Liu, W. Mao, and X. Liu, Trans. Nonferrous Met. Soc. China 19, 1098 (2009).

24. S. Nafisi, D. Emadi, M. T. Shehata, and R. Ghomashchi, Mater. Sci. Eng. A 432, 71 (2006).

25. A. L. Greer, P. S. Cooper, M. W. Meredith, W. Schneider, P. Schumacher, A. Spittle, and J. A. Tronche, Adv. Eng. Mater. 5, 81 (2003).

26. S. G. Shabestari and J. E. Gruzleski, Metall. Mater. Trans. A 26, 999 (1995).

27. L. A. Narayanan, F. H. Samuel, and J. E. Gruzleski, Metall. Trans. A 251761 (1994).

28. W. Jie, Z. Chen, W. Reif, and K. Muller, Metall. Mater. Trans. A 34, 799 (2003).

29. L. F. Mondolfo, Aluminium Alloys: Structure and Properties, p.534, Butterworth, London (1976).
30. P. N. Crepeau, AFS Trans. 103, 361 (1995).

31. Y. Awano and Y. Shimizu, AFS Trans. 98, 889 (1990).

32. X. Bian, G. Chang, and J. Ma, Cast Metals 5, 39 (1992).

33. S. Ji, Y. Wang, D. Watson, and Z. Fan, Metall. Mater. Trans. A 44, 3185 (2013).

34. S. Ji, D. Watson, Z. Fan, and M. White, Mater. Sci. Eng. A 556, 824 (2012).

35. S. L. Chen, S. Daniel, F. Zhang, Y.A. Chang, X. Y. Yan, F. Y. Xie, R. Schmid-Fetzef, and W. A. Oates, Calphad 26, 175 (2002).

36. F. Shimojo, S. Munejiri, K. Hoshino, and Y. Zempo, J. Phys. Condens. Matter. 12, 6161 (2000).

37. F. Q. Zu, Z. G. Zhu, L. J. Guo, B. Zhang, J. P. Shui, and C. S. Liu, Phys. Rev. B 64, 180203 (2001).

38. F. Q. Zu, L. J. Guo, Z. G. Zhu, and Y. Feng, Chin. Phys. Letts. 19, 94 (2002).

39. F. Q. Zu, Z. G. Zhu, L. J. Guo, X. B. Qin, H. Yang, and W. J. Shan, Phys. Rev. Lett. 80, 12505 (2002).

40. F. Q. Zu, Z. G. Zhu, B. Zhang, Y. Feng, and J. P. Shui, J. Phys. Condens. Matter. 13, 11435 (2001).

41. W. Wang, X. Bian, and J. Qin, Chin. J. Mater. Res. 13, 58 (1999).

42. X. Bian and W. Wang, Mater. Lett. 44, 54 (2000).

43. X. Liu, X. Bian, X. Qi, and J. Ma, Trans. Nonferr. Met. Soc. China. 9, 806 (1999).

44. J. Qin, X. Bian, W. Wang, J. Ma, and C. Xu, Chin. Sci. Bull. 43, 1219 (1998).

45. I. G. Brodova, P. S. Popel, and G. I. Eskin, Liquid Metal Processing: Application to Aluminium Alloy Production, Advances in Metallic Alloys, Taylor \& Francis, London (2002).

46. D. A. Porter and K. E. Easterling, Phase Transformation in Metals and Alloys, $2^{\text {nd }}$ ed., Chapman \& Hall, London (1992). 